pneumonia has been also commented upon by other experts in the field $[5,6]$. Thus, the present authors believe that the prophylactic administration of antimicrobials via the respiratory tract for ventilator-associated pneumonia deserves the attention of investigators. However, future studies should focus not only on the effectiveness of this strategy but also on safety and the issue of emergence of antimicrobial resistance.

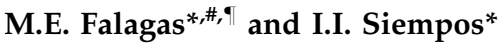

*Alfa Institute of Biomedical Sciences, and "Dept of Medicine, Henry Dunant Hospital, Athens, Greece. "Dept of Medicine, Tufts University School of Medicine, Boston, MA, USA.

\section{STATEMENT OF INTEREST}

None declared.

\section{REFERENCES}

1 Lorente L, Blot S, Rello J. Evidence on measures for the prevention of ventilator-associated pneumonia. Eur Respir J 2007; 30: 1193-1207.
2 Dodek P, Keenan S, Cook D, et al. Evidence-based clinical practice guideline for the prevention of ventilator-associated pneumonia. Ann Intern Med 2004; 141: 305-313.

3 Falagas ME, Siempos II, Bliziotis IA, Michalopoulos A. Administration of antibiotics via the respiratory tract for the prevention of ICU-acquired pneumonia: a meta-analysis of comparative trials. Crit Care 2006; 10: R123.

4 Claridge JA, Edwards NM, Swanson J, et al. Aerosolized ceftazidime prophylaxis against ventilator-associated pneumonia in high-risk trauma patients: results of a double-blind randomized study. Surg Infect (Larchmt) 2007; 8: 83-90.

5 MacIntyre NR, Rubin BK. Respiratory therapies in the critical care setting. Should aerosolized antibiotics be administered to prevent or treat ventilator-associated pneumonia in patients who do not have cystic fibrosis? Respir Care 2007; 52: 416-421.

6 Dhand R. The role of aerosolized antimicrobials in the treatment of ventilator-associated pneumonia. Respir Care 2007; 52: 866-884.

\title{
Competitive swimmers with allergic asthma show a mixed type of airway inflammation
}

\section{To the Editors:}

Elite swimmers are at increased risk of asthma [1]. This has been attributed to airway inflammation and increased airway responsiveness induced by high-intensity long-term exercise and repeated exposure to the chlorine-rich atmosphere in swimming pools during training and competition [2, 3] Recently, increased levels of leukotriene (LT) $\mathrm{B}_{4}$ in exhaled breath condensate and normal exhaled nitric oxide fraction ( $F$ eNO) levels have been reported in five elite swimmers, suggesting possible underlying neutrophilic airway inflammation [4]. Previous analysis of induced sputum in nonasthmatic elite swimmers showed increased proportion of eosinophils and neutrophils compared with healthy controls [3].

We aimed to characterise the airway inflammation in competitive asthmatic swimmers. Athletes from the FC Porto main swimming team and 20 nonathlete asthmatics were recruited; participants gave informed consent. Subjects were classified by their asthma and training status as asthmatic swimmers $(n=6$, two female, aged $17 \pm 2$ yrs, competing $8 \pm 3$ yrs, training $16 \pm 4 \mathrm{~h} \cdot$ week $\left.^{-1}\right)$, asthmatics $(n=20$, eight female, aged $14 \pm 3$ yrs) and swimmers $(n=20$, six female, aged $17 \pm 2$ yrs, competing $8 \pm 3$ yrs, training $17 \pm 3 \mathrm{~h} \cdot$ week $^{-1}$ ).

All asthmatics and nine (45\%) of the swimmers were atopic according to skin-prick test results. None smoked. During two visits to the clinic, 1 week apart, subjects' sputum cell counts, FeNO, lung volumes and airway responsiveness to methacholine (provocative dose causing a $20 \%$ fall in forced expiratory volume in one second (FEV1); PD20) were determined. Sputum cell counts were further compared with reference values from a group of healthy schoolchildren $(n=15$, five female, aged $9 \pm 2$ yrs, $40 \%$ atopic) [5].

Sputum was examined as described previously [3]. Briefly, after induction using an inhalation of hypertonic saline, sputum was selected and treated with dithiothreitol (Sputolysin ${ }^{\circledR}$; Calbiochem Corporation, San Diego, CA, USA). The suspension was centrifuged and the cell pellet was resuspended. Cytospins were prepared and stained using May-Grünwald/Giemsa. Differential cell counts were made by counting a minimum of 500 nonsquamous cells. FeNO was measured by chemiluminescence (NIOX; Aerocrine, Stockholm, Sweden) and PD20 methacholine was determined using the dosimeter method, according to recommendations [6, 7]. ANOVA was used to detect differences between groups. Due to the skewed distribution, eosinophil counts and PD20 methacholine comparisons were made after logarithmic transformation. In order to permit analysis in the log scale, a constant (0.01) was added to each value to eliminate 0 values. A p-value $<0.05$ was considered to be stastically significant.

Induced sputum samples of asthmatic swimmers showed increased numbers of eosinophils and neutrophils compared with both healthy subjects and asthmatic patients respectively, and lymphocytes compared with healthy subjects, although the numbers were approximately the same as in swimmers or 

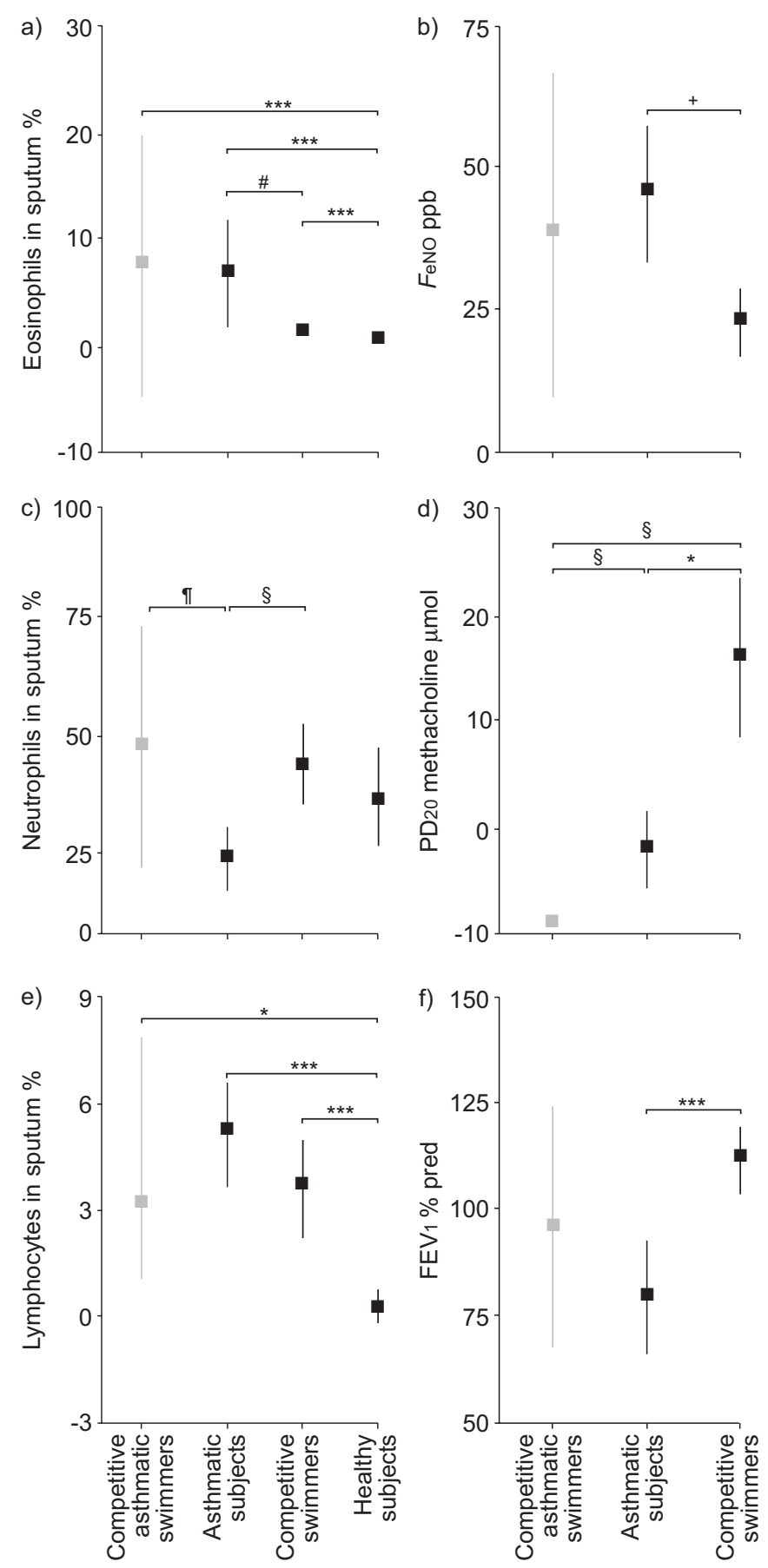

FIGURE 1. Per cent sputum a) eosinophils, c) neutrophils and e) lymphocytes and b) exhaled nitric oxide ( $(\mathrm{eNO}) \mathrm{ppb}, \mathrm{d})$ airway responsiveness provocative dose of methacholine causing a 20\% fall in forced expiratory volume in one second (PD20 methacholine) and f) lung function (\% predicted forced expiratory volume in one second (FEV1)) in competitive asthmatic swimmers (study subjects) compared with asthmatic subjects, competitive swimmers and healthy subjects (controls). Boxes represent mean and whiskers represent confidence intervals. ${ }^{\#:} p=0.015{ }^{+}$: $p=0.002 ;$ : $p=0.005 ;{ }^{\text {s. }}: p=0.001 ;{ }^{*}: p<0.05 ;{ }^{* *}: p<0.001$.

asthmatic patients. Asthmatic swimmers had a similar magnitude of FeNO but significantly more pronounced airway responsiveness than asthmatics (fig. 1).
Features of asthma in competitive swimmers seem to be the result of mixed type effects. Although the cross-sectional nature of our study does not allow us to establish causal relationships, allergic inflammation results in sputum eosinophilia and increased FeNO, while sputum neutrophils may result from the daily exposure of the pool training environment. Increased bronchial responsiveness and lymphocyte numbers could be the result of both processes as they occurred similarly in swimmers and asthmatics.

Two factors could contribute to the neutrophilic airway inflammation in asthmatic competitive swimmers. First, endurance exercise associated hyperventilation and the inhalation of hypotonic aerosolised droplets from the pool surface during training may cause epithelial damage [1] and subsequent inflammation. Secondly, chronic low-grade exposure to chlorine derivatives may be related to the observed increased levels of exhaled $\mathrm{LTB}_{4}$ in elite swimmers [4]. This observation is also supported by the findings in children accidentally exposed to chlorine, with development of respiratory symptoms, lung function impairment and exhaled breath alterations, represented mainly by an increase in LTs and a decrease in FeNO [8]. If this is the case, new therapeutic approaches that, in addition to inhaled corticosteroids, would target the 5-lipoxygenase pathway could have a role attenuating the neutrophilic airway inflammation in swimmers with asthma.

In conclusion, asthma in allergic competitive swimmers is characterised by mixed type of eosinophilic and neutrophilic inflammation, which increase normal exhaled nitric oxide fraction and cause airway hyperresponsiveness. Daily exposure to aerosolised water droplets and chlorine derivatives probably contribute to the neutrophilic inflammation, which might respond poorly to standard asthma medication.

\section{A. Moreira*,\# , L. Delgado*,\#, C. Palmares*, C. Lopes*,\#, T. Jacinto\#, P. Rytilä ${ }^{\top}$, J.A. Silva ${ }^{+}$, M.G. Castel-Branco ${ }^{\#}$ and T. Haahtela}

*Dept of Immunology, Faculty of Medicine, University of Porto, "Immuno-allergology, Hospital of São João, and ${ }^{+} \mathrm{FC}$ Porto Swimming Section, Porto, Portugal. "Skin and Allergy Hospital, Helsinki University Central Hospital, Helsinki, Finland.

\section{SUPPORT STATEMENT}

A. Moreira holds a Grant from the Finnish Centre for International Mobility and a Fellowship Award from the European Academy of Allergy and Clinical Immunology.

\section{STATEMENT OF INTEREST}

A statement of interest for this manuscript can be found at www.erj.ersjournals.com/misc/statements.shtml

\section{ACKNOWLEDGEMENTS}

The present authors would like to thank all subjects for their participation and the technical and administrative staff of FC Porto Swimming Section for logistical help. They would also like to thank S. Simões (Dept of Immunology, Faculty of Medicine, University of Porto, Porto, Portugal) for help with 
data collection and J. Fonseca (Biostatistics and Medical Informatics, Faculty of Medicine, University of Porto and Immuno-allergology, Hospital of São João, Porto, Portugal) for manuscript revision.

\section{REFERENCES}

1 Helenius I, Haahtela T. Allergy and asthma in elite summer sport athletes. J Allergy Clin Immunol 2000; 106: 444-452.

2 Helenius IJ, Tikkanen HO, Sarna S, Haahtela T. Asthma and increased bronchial responsiveness in elite athletes: atopy and sport event as risk factors. J Allergy Clin Immunol 1998; 101: 646-652.

3 Helenius IJ, Rytilä P, Metso T, Haahtela T, Venge P, Tikkanen HO. Respiratory symptoms, bronchial responsiveness, and cellular characteristics of induced sputum in elite swimmers. Allergy 1998; 53: 346-352.

4 Piacentini GL, Rigotti E, Bodini A, Peroni D, Boner AL. Airway inflammation in elite swimmers. J Allergy Clin Immunol 2007; 119: 1559-1560.

5 Rytilä P, Pelkonen AS, Metso T, Nikander K, Haahtela T, Turpeinen $\mathrm{M}$. Induced sputum in children with newly diagnosed mild asthma: the effect of 6 months of treatment with budesonide or disodium cromoglycate. Allergy 2004; 59: 839-844.

6 American Thoracic Society, European Respiratory Society. ATS/ERS recommendations for standardized procedures for the online and offline measurement of exhaled lower respiratory nitric oxide and nasal nitric oxide, 2005. Am J Respir Crit Care Med 2005; 171: 912-930.

7 Sterk PJ, Fabbri LM, Quanjer PhH, et al. Airway responsiveness. Standardized challenge testing with pharmacological, physical and sensitizing stimuli in adults. Report Working Party Standardization of Lung Function Tests, European Community for Steel and Coal. Official Statement of the European Respiratory Society. Eur Respir J 1993; 6: Suppl. 16, 53-83.

8 Bonetto G, Corradi M, Carraro S, et al. Longitudinal monitoring of lung injury in children after acute chlorine exposure in a swimming pool. Am J Respir Crit Care Med 2006; 174: 545-549.

\section{Idiopathic pulmonary fibrosis and nonspecific interstitial pneumonia should stay separate}

\section{To the Editors:}

We read with interest the recent perspective by MAHER et al. [1], challenging the current definition of idiopathic pulmonary fibrosis (IPF). Questioning dogma is critical to progress in science and the authors should be commended for doing so.

We agree that the relationship between disease entity (i.e. clinical diagnosis) and histopathological pattern is more complex than simply equating IPF with usual interstitial pneumonia (UIP), and that distinguishing idiopathic UIP from idiopathic nonspecific interstitial pneumonia (NSIP) can sometimes be difficult, even for expert clinicians, radiologists and pathologists [2]. Indeed, the American Thoracic Society/ European Respiratory Society Consensus Statement made these points quite deliberately [3].

However, we disagree with the authors' contention that "idiopathic UIP and idiopathic NSIP, sharing a common clinical phenotype, form a spectrum of disease with a common pathogenesis" [1]. This blanket statement assumes a homogeneity to idiopathic NSIP and idiopathic UIP that is contrary to the evidence. The idea of a distinct clinical phenotype for idiopathic NSIP is supported by demographic, serological and survival differences seen when IPF and idiopathic NSIP patients are compared [4-6], and by the differences, not similarities, seen in gene expression profiles (six of 10 published NSIP profiles are distinct from UIP while four are similar) $[7,8]$.
It is our belief that idiopathic nonspecific interstitial pneumonia represents a collection of conditions including occult connective tissue disease, hypersensitivity pneumonia and, perhaps, truly idiopathic cases, and should not be lumped together clinically with idiopathic pulmonary fibrosis. We share the hope of MAHER et al. [1] that new and emerging methods of categorising disease will allow us to better understand the relationship of histopathology to pathogenesis and to refine future definitions and diagnostic criteria.

\section{H.R. Collard and T.E. King Jr}

Dept of Medicine, University of California, San Francisco, CA, USA.

\section{STATEMENT OF INTEREST}

None declared.

\section{REFERENCES}

1 Maher TM, Wells AU, Laurent GJ. Idiopathic pulmonary fibrosis: multiple causes and multiple mechanisms? Eur Respir J 2007; 30: 835-839.

2 Flaherty KR, King TE Jr, Raghu G, et al. Idiopathic interstitial pneumonia: what is the effect of a multidisciplinary approach to diagnosis? Am J Respir Crit Care Med 2004; 170: 904-910. 